\title{
Recurrent Salivary Gland Carcinoma
}

National Cancer Institute

\section{Source}

National Cancer Institute. Recurrent Salivary Gland Carcinoma. NCI Thesaurus. Code C7926.

The reemergence of salivary gland carcinoma after a period of remission. 